\title{
Role of exercise in age-related sarcopenia
}

\author{
Su-Zi Yoo', Mi-Hyun No', Jun-Won Heo', Dong-Ho Park', Ju-Hee Kang'², So Hun Kim³ , Hyo-Bum Kwak',* \\ 'Department of Kinesiology, Inha University, Incheon, Korea \\ ${ }^{2}$ Department of Pharmacology and Medicinal Toxicology Research Center, Inha University School of Medicine, Incheon, Korea \\ ${ }^{3}$ Department of Internal Medicine, Inha University School of Medicine, Incheon, Korea
}

Sarcopenia is an age-associated decline of skeletal muscle mass and function and is known to lead to frailty, cachexia, osteoporosis, metabolic syndromes, and death. Notwithstanding the increasing incidence of sarcopenia, the molecular and cellular mechanisms driving age-related sarcopenia are not completely understood. This article reviews current definitions of sarcopenia, its potential mechanisms, and effects of exercise on sarcopenia. The pathogenesis of age-related sarcopenia is multifactorial and includes myostatin, inflammatory cytokines, and mitochondria-derived problems. Especially, age-induced mitochondrial dysfunction triggers the production of reactive oxygen species (ROS) by mitochondria, impedes mitochondrial dynamics, interrupts mitophagy, and leads to mitochondria-mediated apoptosis. Aerobic exercise provides at least a partial solution to sarcopenia as it ameliorates mitochondria-derived problems, and resistance exercise strengthens muscle mass and function. Furthermore, combinations of these exercise types provide the benefits of both. Collectively, this review summarizes potential mechanisms of age-related sarcopenia and emphasizes the use of exercise as a therapeutic strategy, suggesting that combined exercise provides the most beneficial means of combating age-related sarcopenia.

Keywords: Aging, Exercise, Mitochondria, Sarcopenia, Skeletal muscle

\section{INTRODUCTION}

Skeletal muscle is an important organ as it supports the body and enables locomotion. However, skeletal muscle can be degraded by aging, poor nutrition, disuse, and changes in hormonal levels. This phenomenon is called 'sarcopenia', which is known to lead to frailty, cachexia, osteoporosis, metabolic syndromes, and death.

Sarcopenia was first presented by Irwin Rosenberg in 1989 to account for age-related muscle mass decline. However, over recent years its definition has been extended to include low muscle mass and poor muscle function. Indeed, the European Working Group on Sarcopenia in Older People proposed that low muscle mass and low muscle function (strength or performance) both be considered essential diagnostic features of sarcopenia (Cruz-Jentoft et al., 2010).

Clinical criteria for sarcopenia vary from country to country, though cutoff points are generally reported in terms of muscle mass, strength, and physical performance. Limb muscle mass is usually estimated by dual energy X-ray absorptiometry and calculated appendicular skeletal muscle mass is then divided by height squared $\left(\mathrm{kg} / \mathrm{m}^{2}\right)$ to produce skeletal muscle mass index (SMI). Sarcopenia is indicated by a SMI $>2$ standard deviations below the average value for healthy young men or women (Cooper et al., 2013). In addition, SMI has gender-specific cutoff points, that is, $7.26 \mathrm{~kg} / \mathrm{m}^{2}$ for men and $5.45 \mathrm{~kg} / \mathrm{m}^{2}$ for women (Taaffe et al., 2005). On the other hand, muscle strength is usually assessed by measuring grip strength, which is defined as maximum measured grip strength. The diagnostic criteria for grip strength are 26-30 $\mathrm{kg}$ for men and 16-20 kg for women (Heo et al., 2017). Physical performance is usually assessed by measuring habitual gait speed. 'Sarcopenia with limited mobility' is described as a habitual gait speed of $<1.0 \mathrm{~m} / \mathrm{sec}$ over a 4 -m course or a walking distance of $<400 \mathrm{~m}$ in a 6-min walk test (Cooper et al., 2013). As mentioned above, the criteria used to define sarcopenia vary from country to country and sarcopenia can be assessed in multiple ways.

\footnotetext{
*Corresponding author: Hyo-Bum Kwak (iD https://orcid.org/0000-0003-0451-4554 Department of Kinesiology, Inha University, 100 Inha-ro, Nam-gu, Incheon 22212, Korea

Tel: +82-32- 860-8183, Fax: +82-32-860-8188, E-mail: kwakhb@inha.ac.kr

Received: May 16, 2018 / Accepted: June 14, 2018
}

This is an Open Access article distributed under the terms of the Creative Commons Attribution Non-Commercial License (http://creativecommons.org/licenses/by-nc/4.0/) which permits unrestricted non-commercial use, distribution, and reproduction in any medium, provided the original work is properly cited. 


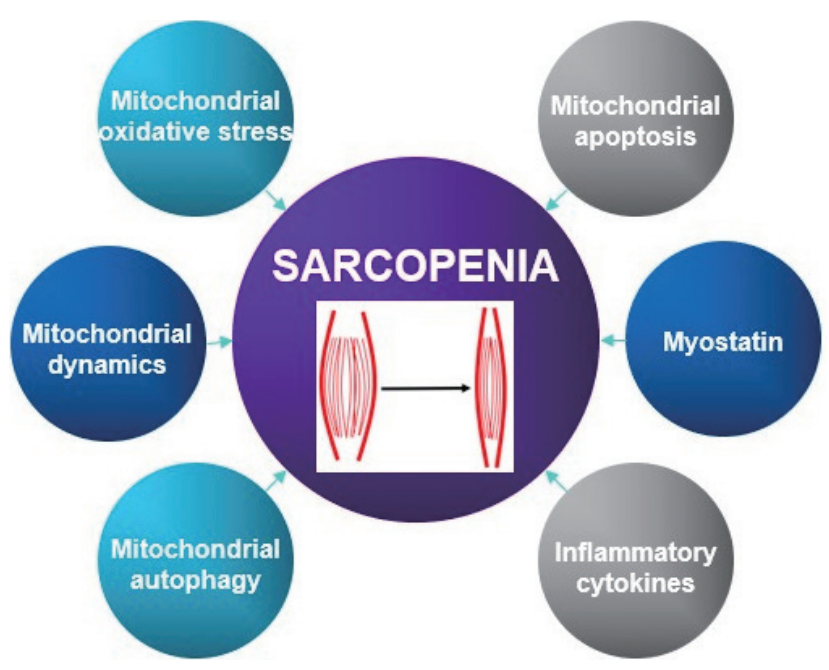

Fig. 1. Potential mechanisms of age-related sarcopenia.

\section{POTENTIAL MECHANISMS OF AGE-RELATED SARCOPENIA}

A variety of factors and pathways are involved in the pathogenesis of sarcopenia, such as, environmental causes, endocrine problems, motor neuron loss, activation of inflammatory pathways, and reductions in satellite cell counts (Cruz-Jentoft et al., 2010). Moreover, recent research suggests mitochondrial dysfunction and the activation of apoptotic signaling are critical aspects of the pathogenesis of age-related sarcopenia. In this review, we focus on potential causes of age-related sarcopenia. Fig. 1 summarizes proposed mechanisms.

\section{Mitochondrial reactive oxygen species \& mitochondrial dysfunction}

Mitochondrial reactive oxygen species (mtROS) is closely related to oxidative stress in aging skeletal muscle and is a major cause of age-induced sarcopenia. The accumulation of mitochondrial ROS in aging skeletal muscle leads to tissue degradation, skeletal muscle atrophy, muscle dysfunction, and increases in fibrous tissue (Heo et al., 2017). mtROS production is associated with mitochondrial DNA (mtDNA) mutations induced by oxidative stress and these mutations result in defective electron transport chain (ETC) components (Alexeyev, 2009). The incorporations of defective subunits into the ETC disrupts oxidative phosphorylation, reduces ATP synthesis, and further increases ROS production (Alexeyev, 2009). Indeed, Wanagat et al. (2001) reported muscle fibers with mtDNA deletions displayed electron transport system abnormalities and fiber atrophy, and Hiona et al. (2010) showed rates of mitochondrial respiration and ATP production were dramatically lower in the skeletal muscles of mtDNA mutant mice. Consequently, age-induced mtROS, mtDNA mutation, and mitochondrial dysfunction are considered potential causes of sarcopenia (Alexeyev, 2009).

\section{Mitochondrial apoptosis}

Apoptosis is a highly programmed form of cell death (Leeuwenburgh, 2003) that can be characterized by cell fragmentation, loss of muscle fibers, and muscle atrophy in skeletal muscle. Mitochondria play a major role during apoptosis, and mitochondrial dysfunctions and mtROS trigger the initial events of mitochondria-mediated apoptosis by causing the release of proapoptotic proteins into cytosol (Leeuwenburgh, 2003). Imbalance between pro-apoptotic protein (Bax) and antiapoptotic protein $(\mathrm{Bcl}-2)$ in mitochondria induces mitochondrial permeability transition pore (mPTP) opening and the release of cytochrome $\mathrm{c}$ from mitochondria to cytosol, which then binds to apoptotic protease-activating factor-1 (Apaf-1) and pro-caspase 9, activates caspase-3, and eventually causes DNA fragmentation (Heo et al., 2017; Leeuwenburgh, 2003). In addition, apoptosis is also triggered by a caspase-independent pathway whereby endonuclease $G$ and apoptosis-inducing factor (AIF) directly trigger DNA fragmentation in mitochondria (Marzetti and Leeuwenburgh, 2006). Previous studies have presented evidence that mitochondrial apoptosis is induced in senescent skeletal muscle. Song et al. (2006) reported the expression of Bax protein is elevated and the expression of $\mathrm{Bcl}-$ 2 is diminished in senescent skeletal muscle (Song et al., 2006), and similarly Gouspillou et al. (2014) found mPTP was more sensitive in vastus lateralis muscles of older men (Gouspillou et al., 2014). Moreover, Siu et al. (2005) showed dramatic increases in AIF contents and apoptotic DNA fragmentation in gastrocnemius muscles of aged rodents. Thus, mitochondria-mediated apoptosis appears to be a major cause of age-induced sarcopenia.

\section{Mitochondrial dynamics}

Function and structure of skeletal muscle fibers are mainly affected by mitochondrial dynamics and morphology (shape and size), which are both induced by intracellular and extracellular signals (Seo et al., 2010a). These changes in the mitochondrial dynamics and morphologies are controlled by continuous fusion and fission. Mitochondrial fusion can compensate for mitochondrial impairment, whereas mitochondrial fission can preserve function by separating dysfunctional mitochondria from healthy mitochondria (Ni et al., 2015). Furthermore, impaired mitochondria may 
fail their fusion process by inactivating fusion or activating fission machineries and thus prevent damaged mitochondria from being reincorporated into the healthy mitochondrial network ( $\mathrm{Ni}$ et al., 2015). Thus, mitochondrial dynamics not only determines the shapes of intracellular organelles but also has substantial effects on mtDNA regulation and mitochondrial function. Dynamin-related guanosine triphosphatases, optic atrophy 1 (OPA 1), and mitofusin 1 (Mfn 1) and its paralog mitofusin 2 (Mfn 2) (Seo et al., 2010a) have been shown to be involved in mitochondrial fusion.

Mfn 1 and Mfn 2 in the outer mitochondrial membrane tether adjacent mitochondria, whereas OPA 1 in the inner mitochondrial membrane mediates inner mitochondrial membrane fusion (Archer, 2013). Westermann identified the proteins involved in mitochondrial fission as dynamin-related protein 1 (Drp 1) and fission protein (Fis 1) (Westermann, 2010). Imbalances of mitochondrial dynamics negatively affect mitochondrial homeostasis and function, and it has been recently reported that in skeletal muscle these imbalances induce senescence and muscle atrophy. For example, Chen et al. (2010) reported that deletion of Mfn 1 and Mfn 2 led to mtDNA mutation, and that accumulations of mtDNA mutations resulted in mitochondrial dysfunction and muscle atrophy. In addition, Romanello et al. (2010) observed overexpression of Drp 1 and Fis 1 triggered mitochondrial fragmentation and dysfunction, activated mitochondrial autophagy (mitophagy), and caused muscle fiber atrophy.

\section{Mitochondrial autophagy}

Mitophagy is type of autophagy that results in the removal of unnecessary or impaired mitochondria. Mitophagy usually begins when membrane potential in skeletal muscle is lost because of aging and is preceded by mitochondrial fission. Recently, mitophagy in skeletal muscle has received greater research attention, especially in the context of muscle atrophy (Yan et al., 2012). Several authors have suggested that mitophagy dysfunction may not be properly utilized due to aging, considering observations of reduced mitochondrial biogenesis and continuous accumulations of damaged organelles (Heo et al., 2017). For example, it has been reported the expressions of autophagy related genes, such as, LC3, Atg7, p62, Beclin 1, Bnip 3, Parkin are reduced by aging (Heo et al., 2017). In addition, Romanello et al. (2010) reported BNIP3 overexpression induced mitochondrial fragmentation, higher levels of autophagy, and muscle atrophy (Joseph et al., 2013; Romanello et al., 2010), and Pagano et al. (2015) reported higher expressions of Beclin 1 and LC3 II in skeletal muscles of sarcopenic 15 - to 22-years-old dogs than 2- to 5 -years-old dogs. Collec- tively, it would appear mitophagy is critical for the maintenance of mitochondrial function and muscle mass.

\section{Myostatin}

Myostatin is an extracellular cytokine and a member of the transforming growth factor $\beta$ superfamily, playing a negative role in regulating skeletal muscle mass and growth (Elkina et al., 2011). During embryogenesis, myostatin is exclusively expressed in skeletal muscle and controls the differentiation and proliferation of myoblasts (Elkina et al., 2011) by inhibiting the expression of insulin-like growth factor (IGF-1) or of follistatin, which is known to be positively related with muscle hypertrophy. Furthermore, it has been reported myostatin is associated with aging. Indeed, Yarasheski et al. (2002) reported that increases in serum myostatin levels were highest in physically frail older women and that they were inversely associated with skeletal muscle mass (White and LeBrasseur, 2014). Siriett et al. (2007) showed that myoD and Pax7 (potent markers of myogenesis) protein levels were significantly elevated in gastrocnemius muscles from aged mice treated with a myostatin antagonist. However, several authors have failed to demonstrate age-related changes in myostatin mRNA levels in skeletal muscle or in circulating myostatin-immunoreactive protein levels (White and LeBrasseur, 2014). Thus, it seems further studies are needed to resolve conflicting results regarding the relation between myostatin and aging.

\section{Inflammatory cytokines}

It has been demonstrated inflammatory markers contribute to age-related muscle wasting (Budui et al., 2015). For example, elevated levels of tumor necrosis factor alpha (TNF- $\alpha$ ) were found to increase muscle catabolism by suppressing the Akt/mammalian target of rapamycin (mTOR) pathway (Budui et al., 2015). It also seems inflammatory cytokines may antagonize the anabolic effect of IGF-1 by inducing the development of growth hormone resistance, which decreases both circulating and muscle IGF-1 levels (Budui et al., 2015). However, the effects of these cytokines may be more complex because interleukin 6 (IL-6) may play a role, and it can act as pro- or anti-inflammatory cytokine (Rolland et al., 2008). Recent experimental studies have suggested that IL-6 in blood can be differentiated from muscle-derived IL-6, which can inhibit TNF- $\alpha$ (Rolland et al., 2008). The involvements of cytokines in sarcopenia remain to be clarified, but nonetheless, sarcopenia appears to be a cytokine-associated aging phenomenon (Rolland et al., 2008). 


\section{EFFECTS OF EXERCISE ON SARCOPENIA}

Exercise is essential for health because it increases muscle mass, reduces body fat, and improves muscle strength, endurance, immune function, and the cardiovascular system. Accordingly, exercise should be considered an essential feature of therapeutic strategies targeting age-related sarcopenia. Here, we briefly describe the effects of aerobic, resistance, and combined exercises on age-related sarcopenia.

\section{Aerobic exercise and sarcopenia}

Aerobic exercise causes ATP production in mitochondria within skeletal muscle, and improves aerobic capacity, metabolic regulation, and cardiovascular function. Furthermore, it contributes to the inductions of mitochondrial biogenesis and dynamics, to the restoration of mitochondrial metabolism, reduces the expressions of catabolic genes and increases muscle protein synthesis (Erlich et al., 2016; Konopka and Harber, 2014; Seo et al., 2016). Previous studies have shown endurance exercise training may suppress the apoptotic pathway in skeletal muscle and that aerobic exercise helps maintain the expression of autophagy protein and may even increase the expressions of autophagy-related proteins in skeletal muscle (Yan et al., 2012). In addition, several authors have shown aerobic exercise controls mRNA expression of myostatin (Ko et al., 2014). Given that these molecular factors are associated with age-related sarcopenia, it seems aerobic exercise has a protective effect. Indeed, Harber et al. (2012) reported that cycle exercise increased muscle size and strength in both 20-years-old and 74-years-old subjects. Moreover, Bori et al. (2012) reported that 12 weeks of aerobic exercise training enhanced mitochondrial biogenesis and mitochondrial fission protein (Fis 1) of older subjects. Collectively, aerobic exercise appears to ameliorate mitochondria-related problems and improve muscle hypertrophy and strength. Table 1 summarizes the effects of aerobic exercise on age-related sarcopenia.

\section{Resistance exercise and sarcopenia}

Resistance exercise is considered an important strategy for preventing muscle wasting because it stimulates muscle hypertrophy and increases muscle strength (Johnston et al., 2008) by shifting the balance between muscle protein synthesis and degradation towards synthesis (Johnston et al., 2008). It is known regular resistance exercise increases the sizes and cross-sectional areas of muscle fibers, especially fast-twitch fibers (types IIa and IIx) rather than

Table 1. Effects of aerobic exercise on age-related sarcopenia

\begin{tabular}{|c|c|c|c|c|c|}
\hline Subject & Sex & Age & Exercise protocols & Results & References \\
\hline Rat & Male & $28 \mathrm{mo}$ & $\begin{array}{l}\text { Treadmill, } 3 \text { days, } 6 \text { weeks, } \\
60 \% \text { of } \mathrm{VO}_{2 \max }\end{array}$ & $\begin{array}{l}\uparrow \mathrm{mTOR} \text { levels } \\
\uparrow \text { Follistatin protein levels } \\
=\text { Myostatin protein levels }\end{array}$ & Ziaaldini et al. (2015) \\
\hline Mice & Male & $17 \mathrm{mo}$ & Voluntary wheel running & $\begin{array}{l}\uparrow \text { Grip strength } \\
\uparrow \text { Gastrocnemius expression genes (IL-6, Sod1 etc.) }\end{array}$ & Pence et al. (2016) \\
\hline Rat & Male & $24 \mathrm{mo}$ & $\begin{array}{l}\text { Treadmill exercise, } 30 \text { min, } \\
\text { once a day, } 6 \text { weeks }\end{array}$ & $\begin{array}{l}\downarrow \text { Myostatin mRNA expression } \\
\uparrow \text { Myocyte proliferation }\end{array}$ & Ko et al. (2014) \\
\hline Human & Male/female & $65-75 \mathrm{yr}$ & Dance, 60 min for 8 weeks & $\begin{array}{l}\uparrow \text { Muscle mass } \\
\uparrow \text { Back extensor strength }\end{array}$ & Chen et al. (2017) \\
\hline Human & Female & $74 \pm 3 y r$ & $\begin{array}{l}\text { Cycle ergometer, } 3 \text { days/wk for } \\
12 \text { weeks } 20-45 \text { min, } 60 \%-80 \% \text { of HRR }\end{array}$ & $\begin{array}{l}\uparrow \text { SIRT1, AMPK mRNA expression } \\
\uparrow \text { Mitochondrial biogenesis }\end{array}$ & Bori et al. (2012) \\
\hline Human & Male & $74 \mathrm{yr}$ & $\begin{array}{l}\text { Cycle ergometer, } 12 \text { weeks, 20-45 min, } \\
\text { 3-4 day/wk, 60\%-80\% of HRR }\end{array}$ & $\begin{array}{l}\uparrow \text { Quadriceps volume }(-6 \%) \\
\uparrow \text { Muscle size } \\
\uparrow \text { Aerobic capacity }\end{array}$ & Harber et al. (2012) \\
\hline Human & Female & $70 \pm 2 y r$ & $\begin{array}{l}\text { Cycle ergometer, } 12 \text { weeks, } 20-45 \text { min, } \\
\text { 3-4 day/wk, 60\%-80\% of HRR }\end{array}$ & $\begin{array}{l}\uparrow \text { Aerobic capacity } \\
\uparrow \text { Muscle size } \\
\uparrow \text { Muscle strength } \\
\downarrow \text { FOXO3A, Myostatin, MRF4 mRNA expression } \\
\downarrow \text { PGC-1 } \alpha \text { protein levels }\end{array}$ & Konopka et al. (2010) \\
\hline Human & Male/female & $21-87 \mathrm{yr}$ & $\begin{array}{l}\text { Bicycle training, } 3-4 \text { days/wk } 45 \text { min, } \\
80 \% \text { peak heart rate }\end{array}$ & $\begin{array}{l}\uparrow \mathrm{MHC} \text { I and MHC Ila mRNA expression } \\
\downarrow \mathrm{MHC} \| \mathrm{x} \text { mRNA expression }\end{array}$ & Short et al. (2005) \\
\hline
\end{tabular}

$\uparrow$, increase; $\downarrow$, decrease; =, no change; HRR, heart rate reserve; $\mathrm{VO}_{2 m a x}$, maximum rate of oxygen consumption; mTOR, mammalian target of rapamycin; IL-6, interleukin-6; Sod 1, superoxide dismutase 1; FOXO3A, forkheadbox 3A; MRF4, muscle regulatory factor 4; PGC-1 $\alpha$, peroxisome proliferator-activated receptor gamma coactivator $1-\alpha$; AMPK, AMP-activated protein kinase; SIRT 1, sirtuin 1; MHC, myosin heavy chain. 
Table 2. Effects of resistance exercise on age-related sarcopenia

\begin{tabular}{|c|c|c|c|c|c|}
\hline Subject & Sex & Age & Exercise protocols & Results & References \\
\hline Rat & Male & $30 \mathrm{mo}$ & $\begin{array}{l}\text { Stretch-shortening contraction, } \\
2 \text { days/wk }\end{array}$ & $\begin{array}{l}\downarrow \text { Lipid peroxidation } \\
\downarrow \text { Oxidative stress levels } \sim 11 \% \\
\uparrow \text { Tibialis anterior muscle mass } \sim 17 \%\end{array}$ & Rader et al. (2017) \\
\hline Mice & Male/female & $15-23 \mathrm{mo}$ & $\begin{array}{l}\text { Resistance wheel exercise, } \\
34 \text { weeks }\end{array}$ & $\begin{array}{l}\uparrow \text { Soleus muscle mass, } \\
\uparrow \text { Oxidative stress, } \\
\uparrow \text { Mitochondrial density }\end{array}$ & White et al. (2016) \\
\hline Rat & Male & $10 w k$ & $\begin{array}{l}4 \text { weeks group, } 8 \text { weeks group, } \\
\text { Climbing a } 1-3 \text { vertical ladder, } \\
10 \text { times, } 3 \text { days/wk }\end{array}$ & $\begin{array}{l}4 \text { weeks group: } \uparrow \text { Mustn1 mRNA expression } \\
8 \text { weeks group: } \uparrow \text { Mustn1 mRNA expression }\end{array}$ & Oh et al. (2011) \\
\hline Human & Male/female & $73.6 \pm 5.7 \mathrm{yr}$ & RE+LTPA: 12 weeks + 16-18 months & $\begin{array}{l}\uparrow \text { Quadriceps strength (only RE) } \\
\uparrow \text { Time-up-and-go performance (RE+LTPA) }\end{array}$ & Geirsdottir et al. (2015) \\
\hline Human & Male/Female & $78 \mathrm{yr}$ & $\begin{array}{l}\text { Progressive resistance exercise training } \\
\text { (PRT), RE: } 3 \text { months of low intensity, } \\
3 \text { months }\end{array}$ & $\begin{array}{l}\uparrow \text { Maximal voluntary force production for knee extension } \\
\uparrow \text { Total body FFM } \\
=\text { Fat mass }\end{array}$ & Peterson et al. (2010) \\
\hline Human & Male & $60-70 \mathrm{yr}$ & $\begin{array}{l}\text { High and low velocity RE, } \\
2 \text { days/wk for } 10 \text { weeks }\end{array}$ & $\begin{array}{l}\uparrow \text { Arm curling } \\
\uparrow 30 \text {-sec chair-stand } \\
\uparrow \text { Muscle power }\end{array}$ & Bottaro et al. (2007) \\
\hline Human & Male/female & $65-78 \mathrm{yr}$ & $\begin{array}{l}\text { High-intensity RE, 1-2 weeks/20 weeks, } \\
3 \text { sets of } 8 \text { repetitions }\end{array}$ & $\begin{array}{l}\uparrow \text { Muscle function } \\
\uparrow \text { Physical performance }\end{array}$ & Galvão et al. (2005) \\
\hline Human & Male/female & $83 \pm 4 y r$ & $\begin{array}{l}\text { PRT ET: 3-month of light intensity, } \\
\text { 3-month added RE, 3-month added AE }\end{array}$ & $\begin{array}{l}\uparrow \mathrm{VO}_{2 \text { peak }} \\
\uparrow \text { Physical Performance Test }\end{array}$ & Binder et al. (2002) \\
\hline
\end{tabular}

$\uparrow$, increase; $\downarrow$, decrease; =, no change; AE, aerobic exercise; RE, resistance exercise; LTPA, leisure time physical activity; ET, exercise training; FFM, fat free mass; Mustn 1 , musculoskeletal embryonic nuclear protein $1 ; \mathrm{VO}_{2 \text { peak, }}$ peak oxygen uptake.

slow-twitch fibers (type I) (Heo et al., 2017). Increases in muscle protein synthesis and muscle fibers hypertrophy increase forcegenerating ability (Johnston et al., 2008), muscle quality, and physical performance. However, resistance exercise has several limitations. In particular, it has a little effect on the expressions of mitochondrial proteins or their functions, and these are considered potential causes of age-related sarcopenia. Nonetheless, resistance exercise is a meaningful exercise prescription for sarcopenia in terms of improving muscle mass and function. Binder et al. (2002) showed that progressive resistance training resulted in increased physical performance and peak oxygen uptake. Bottaro et al. (2007) reported that 10 weeks of resistance exercise enhanced physical activities, including arm curling and 30-sec chair-stand. In addition, Peterson et al. (2010) showed 3 months of resistance exercise improved maximal force production of knee extension and total body fat free mass. Table 2 provides a summary of the effects of resistance exercise on age-related sarcopenia.

\section{Combined exercise and sarcopenia}

The majority of studies on the effects of exercise have focused on either aerobic or resistance exercise. As mentioned above, aerobic exercise has a little effect on muscle strength or mass compared with resistance exercise (Lee, 2017; Takeshima et al., 2004), whereas resistance exercise can increase the risk of injury, reduce participation rates, and induce boredom because of the extent of repetition (Lee, 2017). Also, resistance exercise can be less effective in older individuals because of deficient mTOR signaling, which is involved in muscle protein synthesis (Heo et al., 2017). Accordingly, no single type of exercise would seem to address adequately the requirements of therapeutic exercise in age-related sarcopenia, and thus, it has been recommended well-rounded exercise programs consisting of aerobic and resistance exercises should be preferred (Takeshima et al., 2004). For example, a circuit exercise program has been developed that combines these two exercise types (Lee, 2017; Takeshima et al., 2004). Recently, Lee et al. (2017) reported that 12 weeks of circuit program improved walking and balancing abilities and isokinetic muscle functions. Gudlaugsson et al. (2013) showed 'multimodal training interventions' conducted on 117 elderly subjects for 6 months improved endurance performance as determined by 6-min walking test. Collectively, these reports indicate regular combined exercise can be utilized to combat age-related sarcopenia. Further research is needed to determine whether combined exercise retards potential molecular mechanisms of age-related sarcopenia. Table 3 presents a summary of the effects of combined exercise on age-related sarcopenia. 
Table 3. Effects of combined exercise on age-related sarcopenia

\begin{tabular}{|c|c|c|c|c|c|}
\hline Subject & Sex & Age & Exercise protocols & Results & References \\
\hline Human & Male & $69 \pm 4.9 \mathrm{yr}$ & $\begin{array}{l}1 \text { time for } 1 \mathrm{hr} \text {, moderated to vigorous intensity } \\
\text { for } 32 \text { weeks }\end{array}$ & $\begin{array}{l}\uparrow 6 \text {-min walk test } \\
\uparrow 30 \text {-sec chair-stand } \\
\uparrow \text { Functional reach test }\end{array}$ & Sousa et al. (2017) \\
\hline Human & Female & $>60 \mathrm{yr}$ & $\begin{array}{l}1 \text { time for } 50 \text { min, } 3 \text { times/wk, AE: treadmill, } \\
\text { RE: knee flexion, arm raise, squat for } 12 \text { weeks }\end{array}$ & $\begin{array}{l}\uparrow \text { Lean mass, } \\
\downarrow \text { Body weight, } \\
\downarrow \text { Body fat }\end{array}$ & Bocalini et al. (2012) \\
\hline Human & Male/female & $71-90 \mathrm{yr}$ & AE of 5 day/wk, RE of 2 day/wk for 6 months & $\begin{array}{l}\uparrow \text { Shorts physical performance battery } \\
\uparrow 8 \text { foot up and go test }\end{array}$ & Gudlaugsson et al. (2013) \\
\hline Human & Male & $40-67 \mathrm{yr}$ & CE: 4 times/wk for 21 weeks & $\begin{array}{l}\uparrow \text { Maximum strength } \\
=\text { type II muscle cross-sectional area }\end{array}$ & Karavirta et al. (2011) \\
\hline Human & Female & $50-65 y r$ & $\begin{array}{l}3 \text { times/wk, } 50 \%-75 \% \text { of } 1 \text { repetition maximum } \\
\text { for } 12 \text { weeks }\end{array}$ & $\begin{array}{l}\uparrow \text { Growth hormone } \\
\downarrow \text { Body fat } \\
\uparrow \text { Metabolic-syndrome factors }\end{array}$ & Seo et al. (2010b) \\
\hline
\end{tabular}

$\uparrow$, increase; $\downarrow$, decrease; =, no change; $A E$, aerobic exercise; $R E$, resistance exercise; $C E$, combined exercise.

\section{CONCLUSIONS}

Mitochondrial oxidative stress, apoptosis, and dynamics, and mitophagy, myostatin, and inflammatory cytokines are all believed to be associated with age-related sarcopenia. Nevertheless, aerobic, resistance, and combined exercise training regimes have been shown to produce the most beneficial preventive and therapeutic effects. Further research is required to elucidate the cellular and molecular mechanisms responsible for protective effect of regular exercise training on age-induced sarcopenia of skeletal muscles.

\section{CONFLICT OF INTEREST}

No potential conflict of interest relevant to this article was reported.

\section{ACKNOWLEDGMENTS}

This work was supported by Inha University Research Grant (2017).

\section{REFERENCES}

Alexeyev MF. Is there more to aging than mitochondrial DNA and reactive oxygen species? FEBS J 2009;276:5768-5787.

Archer SL. Mitochondrial dynamics--mitochondrial fission and fusion in human diseases. N Engl J Med 2013;369:2236-2251.

Binder EF, Schechtman KB, Ehsani AA, Steger-May K, Brown M, Sinacore DR, Yarasheski KE, Holloszy JO. Effects of exercise training on frailty in community-dwelling older adults: results of a randomized, controlled trial. J Am Geriatr Soc 2002;50:1921-1928.

Bocalini DS, Lima LS, de Andrade S, Madureira A, Rica RL, Dos Santos RN, Serra AJ, Silva JA Jr, Rodriguez D, Figueira A Jr, Pontes FL Jr. Effects of circuit-based exercise programs on the body composition of elderly obese women. Clin Interv Aging 2012;7:551-556.

Bori Z, Zhao Z, Koltai E, Fatouros IG, Jamurtas AZ, Douroudos II, Terzis G, Chatzinikolaou A, Sovatzidis A, Draganidis D, Boldogh I, Radak Z. The effects of aging, physical training, and a single bout of exercise on mitochondrial protein expression in human skeletal muscle. Exp Gerontol 2012;47:417-424.

Bottaro M, Machado SN, Nogueira W, Scales R, Veloso J. Effect of high versus low-velocity resistance training on muscular fitness and functional performance in older men. Eur J Appl Physiol 2007;99:257-264.

Budui SL, Rossi AP, Zamboni M. The pathogenetic bases of sarcopenia. Clin Cases Miner Bone Metab 2015;12:22-26.

Chen H, Vermulst M, Wang YE, Chomyn A, Prolla TA, McCaffery JM, Chan DC. Mitochondrial fusion is required for mtDNA stability in skeletal muscle and tolerance of mtDNA mutations. Cell 2010;141:280289.

Chen HT, Chung YC, Chen YJ, Ho SY, Wu HJ. Effects of different types of exercise on body composition, muscle strength, and IGF-1 in the elderly with sarcopenic obesity. J Am Geriatr Soc 2017;65:827-832.

Cooper C, Fielding R, Visser M, van Loon LJ, Rolland Y, Orwoll E, Reid K, Boonen S, Dere W, Epstein S, Mitlak B, Tsouderos Y, Sayer AA, Rizzoli R, Reginster JY, Kanis JA. Tools in the assessment of sarcopenia. Calcif Tissue Int 2013;93:201-210.

Cruz-Jentoft AJ, Baeyens JP, Bauer JM, Boirie Y, Cederholm T, Landi F, Martin FC, Michel JP, Rolland Y, Schneider SM, Topinková E, Vandewoude M, Zamboni M; European Working Group on Sarcopenia in 
Older People. Sarcopenia: European consensus on definition and diagnosis: Report of the European Working Group on Sarcopenia in Older People. Age Ageing 2010;39:412-423.

Elkina Y, von Haehling S, Anker SD, Springer J. The role of myostatin in muscle wasting: an overview. J Cachexia Sarcopenia Muscle 2011;2: 143-151.

Erlich AT, Tryon LD, Crilly MJ, Memme JM, Moosavi ZSM, Oliveira AN, Beyfuss K, Hood DA. Function of specialized regulatory proteins and signaling pathways in exercise-induced muscle mitochondrial biogenesis. Integr Med Res 2016;5:187-197.

Galvão DA, Taaffe DR. Resistance exercise dosage in older adults: singleversus multiset effects on physical performance and body composition. J Am Geriatr Soc 2005;53:2090-2097.

Geirsdottir OG, Arnarson A, Ramel A, Briem K, Jonsson PV, Thorsdottir I. Muscular strength and physical function in elderly adults 6-18 months after a 12-week resistance exercise program. Scand J Public Health 2015; 43:76-82.

Gouspillou G, Sgarioto N, Kapchinsky S, Purves-Smith F, Norris B, Pion $\mathrm{CH}$, Barbat-Artigas S, Lemieux F, Taivassalo T, Morais JA, AubertinLeheudre M, Hepple RT. Increased sensitivity to mitochondrial permeability transition and myonuclear translocation of endonuclease $G$ in atrophied muscle of physically active older humans. FASEB J 2014; 28:1621-1633.

Gudlaugsson J, Aspelund T, Gudnason V, Olafsdottir AS, Jonsson PV, Arngrimsson SA, Johannsson E. The effects of 6 months' multimodal training on functional performance, strength, endurance, and body mass index of older individuals. Are the benefits of training similar among women and men? Laeknabladid 2013;99:331-337.

Harber MP, Konopka AR, Undem MK, Hinkley JM, Minchev K, Kaminsky LA, Trappe TA, Trappe S. Aerobic exercise training induces skeletal muscle hypertrophy and age-dependent adaptations in myofiber function in young and older men. J Appl Physiol (1985) 2012;113:14951504.

Heo JW, No MH, Park DH, Kang JH, Kwak HB. Aging-induced sarcopenia and exercise. Asian J Kinesiol 2017;19:43-59.

Hiona A, Sanz A, Kujoth GC, Pamplona R, Seo AY, Hofer T, Someya S, Miyakawa T, Nakayama C, Samhan-Arias AK, Servais S, Barger J, Portero-Otín M, Tanokura M, Prolla TA, Leeuwenburgh C. Mitochondrial DNA mutations induce mitochondrial dysfunction, apoptosis and sarcopenia in skeletal muscle of mitochondrial DNA mutator mice. PLoS One 2010;5:e11468.

Johnston AP, De Lisio M, Parise G. Resistance training, sarcopenia, and the mitochondrial theory of aging. Appl Physiol Nutr Metab 2008;33: 191-199.

Joseph AM, Adhihetty PJ, Wawrzyniak NR, Wohlgemuth SE, Picca A,
Kujoth GC, Prolla TA, Leeuwenburgh C. Dysregulation of mitochondrial quality control processes contribute to sarcopenia in a mouse model of premature aging. PLoS One 2013;8:e69327.

Karavirta L, Häkkinen A, Sillanpää E, García-López D, Kauhanen A, Haapasaari A, Alen M, Pakarinen A, Kraemer WJ, Izquierdo M, Gorostiaga E, Häkkinen K. Effects of combined endurance and strength training on muscle strength, power and hypertrophy in 40-67-year-old men. Scand J Med Sci Sports 2011;21:402-411.

Ko IG, Jeong JW, Kim YH, Jee YS, Kim SE, Kim SH, Jin JJ, Kim CJ, Chung KJ. Aerobic exercise affects myostatin expression in aged rat skeletal muscles: a possibility of antiaging effects of aerobic exercise related with pelvic floor muscle and urethral rhabdosphincter. Int Neurourol J 2014;18:77-85.

Konopka AR, Douglass MD, Kaminsky LA, Jemiolo B, Trappe TA, Trappe $S$, Harber MP. Molecular adaptations to aerobic exercise training in skeletal muscle of older women. J Gerontol A Biol Sci Med Sci 2010;65: 1201-1207.

Konopka AR, Harber MP. Skeletal muscle hypertrophy after aerobic exercise training. Exerc Sport Sci Rev 2014;42:53-61.

Lee MY, Jun WS, Lee MG. Effects of a 12-week circuit exercise program on fall-related fitness in elderly women with sarcopenia. Korean J Sports Sci 2017;26:1123-1135.

Leeuwenburgh C. Role of apoptosis in sarcopenia. J Gerontol A Biol Sci Med Sci 2003;58:999-1001.

Marzetti E, Leeuwenburgh C. Skeletal muscle apoptosis, sarcopenia and frailty at old age. Exp Gerontol 2006;41:1234-1238.

Ni HM, Williams JA, Ding WX. Mitochondrial dynamics and mitochondrial quality control. Redox Biol 2015;4:6-13.

Oh SL. Effect of resistance exercise training on Mustn1 mRNA expression in rat skeletal muscle. Korean J Sports Med 2011;29:112-117.

Pagano TB, Wojcik S, Costagliola A, De Biase D, Iovino S, Iovane V, Russo V, Papparella S, Paciello O. Age related skeletal muscle atrophy and upregulation of autophagy in dogs. Vet J 2015;206:54-60.

Pence BD, Gibbons TE, Bhattacharya TK, Mach H, Ossyra JM, Petr G, Martin SA, Wang L, Rubakhin SS, Sweedler JV, McCusker RH, Kelley KW, Rhodes JS, Johnson RW, Woods JA. Effects of exercise and dietary epigallocatechin gallate and $\beta$-alanine on skeletal muscle in aged mice. Appl Physiol Nutr Metab 2016;41:181-190.

Peterson MD, Rhea MR, Sen A, Gordon PM. Resistance exercise for muscular strength in older adults: a meta-analysis. Ageing Res Rev 2010;9: 226-237.

Rader EP, Naimo MA, Layner KN, Triscuit AM, Chetlin RD, Ensey J, Baker BA. Enhancement of skeletal muscle in aged rats following high-intensity stretch-shortening contraction training. Rejuvenation Res 2017; 20:93-102. 
Rolland Y, Czerwinski S, Abellan Van Kan G, Morley JE, Cesari M, Onder G, Woo J, Baumgartner R, Pillard F, Boirie Y, Chumlea WM, Vellas B. Sarcopenia: its assessment, etiology, pathogenesis, consequences and future perspectives. J Nutr Health Aging 2008;12:433-450.

Romanello V, Guadagnin E, Gomes L, Roder I, Sandri C, Petersen Y, Milan G, Masiero E, Del Piccolo P, Foretz M, Scorrano L, Rudolf R, Sandri M. Mitochondrial fission and remodelling contributes to muscle atrophy. EMBO J 2010;29:1774-1785.

Seo AY, Joseph AM, Dutta D, Hwang JC, Aris JP, Leeuwenburgh C. New insights into the role of mitochondria in aging: mitochondrial dynamics and more. J Cell Sci 2010a;123(Pt 15):2533-2542.

Seo DI, Jun TW, Park KS, Chang H, So WY, Song W. 12 weeks of combined exercise is better than aerobic exercise for increasing growth hormone in middle-aged women. Int J Sport Nutr Exerc Metab 2010b;20:21-26.

Seo DY, Lee SR, Kim N, Ko KS, Rhee BD, Han J. Age-related changes in skeletal muscle mitochondria: the role of exercise. Integr Med Res 2016; 5:182-186.

Short KR, Vittone JL, Bigelow ML, Proctor DN, Coenen-Schimke JM, Rys $\mathrm{P}$, Nair KS. Changes in myosin heavy chain mRNA and protein expression in human skeletal muscle with age and endurance exercise training. J Appl Physiol (1985) 2005;99:95-102.

Siriett V, Salerno MS, Berry C, Nicholas G, Bower R, Kambadur R, Sharma $\mathrm{M}$. Antagonism of myostatin enhances muscle regeneration during sarcopenia. Mol Ther2007;15:1463-1470.

Siu PM, Pistilli EE, Alway SE. Apoptotic responses to hindlimb suspension in gastrocnemius muscles from young adult and aged rats. Am J Physiol Regul Integr Comp Physiol 2005;289:R1015-1026.

Song W, Kwak HB, Lawler JM. Exercise training attenuates age-induced changes in apoptotic signaling in rat skeletal muscle. Antioxid Redox Signal 2006;8:517-528.

Sousa N, Mendes R, Silva A, Oliveira J. Combined exercise is more effective than aerobic exercise in the improvement of fall risk factors: a randomized controlled trial in community-dwelling older men. Clin Rehabil 2017;31:478-486.

Taaffe DR, Sipilä S, Cheng S, Puolakka J, Toivanen J, Suominen H. The effect of hormone replacement therapy and/or exercise on skeletal muscle attenuation in postmenopausal women: a yearlong intervention. Clin Physiol Funct Imaging 2005;25:297-304.

Takeshima N, Rogers ME, Islam MM, Yamauchi T, Watanabe E, Okada A. Effect of concurrent aerobic and resistance circuit exercise training on fitness in older adults. Eur J Appl Physiol 2004;93:173-182.

Wanagat J, Cao Z, Pathare P, Aiken JM. Mitochondrial DNA deletion mutations colocalize with segmental electron transport system abnormalities, muscle fiber atrophy, fiber splitting, and oxidative damage in sarcopenia. FASEB J 2001;15:322-332.

Westermann B. Mitochondrial fusion and fission in cell life and death. Nat Rev Mol Cell Biol 2010;11:872-884.

White TA, LeBrasseur NK. Myostatin and sarcopenia: opportunities and challenges - a mini-review. Gerontology 2014;60:289-293.

White Z, Terrill J, White RB, McMahon C, Sheard P, Grounds MD, Shavlakadze T. Voluntary resistance wheel exercise from mid-life prevents sarcopenia and increases markers of mitochondrial function and autophagy in muscles of old male and female C57BL/6J mice. Skelet Muscle 2016;6:45.

Yan Z, Lira VA, Greene NP. Exercise training-induced regulation of mitochondrial quality. Exerc Sport Sci Rev 2012;40:159-164.

Yarasheski KE, Bhasin S, Sinha-Hikim I, Pak-Loduca J, Gonzalez-Cadavid NF. Serum myostatin-immunoreactive protein is increased in 60-92 year old women and men with muscle wasting. J Nutr Health Aging 2002;6:343-348.

Ziaaldini MM, Koltai E, Csende Z, Goto S, Boldogh I, Taylor AW, Radak Z. Exercise training increases anabolic and attenuates catabolic and apoptotic processes in aged skeletal muscle of male rats. Exp Gerontol 2015;67:9-14. 